\title{
Paraquat Substituent Effect on Complexation with a Dibenzo-24-Crown-8-Based Cryptand
}

Jinqiang Zhang, ${ }^{\dagger}$ Feihe Huang, ${ }^{*}{ }^{\dagger}$ Ning Li, ${ }^{\dagger}$ Hong Wang, ${ }^{\dagger}$ Harry W. Gibson, ${ }^{*}{ }^{\dagger}$ Peter

Gantzel, ${ }^{`}$ and Arnold L. Rheingold ${ }^{\curlyvee}$

${ }^{\dagger}$ Department of Chemistry, Zhejiang University, Hangzhou 310027, P. R. China. Fax:

+86-571-8795-1895; Tel: +86-571-8795-3189; Email address:fhuang@zju.edu.cn.

${ }^{\star}$ Department of Chemistry, Virginia Polytechnic Institute and State University, Blacksburg, VA, USA 24061-0212. Fax: +01-540-231-8517; Tel: +01-540-231-5902; Email address: hwgibson@vt.edu.

$\checkmark$ Department of Chemistry and Biochemistry, University of California, San Diego, La Jolla, CA, 92093-0358

\section{Supplemental Material (10 pages)}

1. Determination of association constants of $\mathbf{4} \cdot \mathbf{P 1}, \mathbf{4} \cdot \mathbf{P 2}$, and $\mathbf{4} \cdot \mathbf{P} 3 \quad$ S2

2. Partial proton NMR spectra of $\mathbf{4} \cdot \mathbf{P} 2$, and $\mathbf{4} \cdot \mathbf{P} 3$ with integration values $\quad \mathrm{S} 6$

3. HMQC spectrum of a solution of $\mathbf{4}$ and $\mathbf{P 2} \quad \mathrm{S} 7$

$\begin{array}{ll}\text { 4. } X \text {-ray analysis data of } \mathbf{4} \cdot \mathbf{P 2} & \text { S8 }\end{array}$

5. X-ray analysis data of $\mathbf{4} \cdot \mathbf{P 3} \quad$ S8

6. A thermal ellipsoid plot of the X-ray crystal structure of $\mathbf{4} \cdot \mathbf{P 1} \quad$ S9

7. A thermal ellipsoid plot of the X-ray crystal structure of $\mathbf{4} \cdot \mathbf{P} 2 \quad$ S9

8. A thermal ellipsoid plot of the X-ray crystal structure of $\mathbf{4} \bullet \mathbf{P} 3 \quad \mathrm{~S} 10$

9. Calculations of distribution maps of the Mulliken charges of $\mathbf{P 1}$ and $\mathbf{P} 3$ at the AM1 level 


\section{Determination of association constants of $4 \cdot \mathrm{P} 1,4 \cdot \mathrm{P} 2$, and $4 \cdot \mathrm{P3}$.}

$K_{\mathrm{a}, \mathbf{4} \cdot \mathbf{P} 1}, K_{\mathrm{a}, \mathbf{4} \cdot \mathbf{P} 2}$ and $K_{\mathrm{a}, \mathbf{4} \cdot \mathbf{P} 3}$ were determined in the same way. First $16.9 \mathrm{mg}$ of cryptand 4 were added to a $25 \mathrm{~mL}$ volumetric flask. Then acetone was added to give a $1.00 \mathrm{mM}$ solution of 4 . Precisely weighed amounts of guests were dissolved in this $1.00 \mathrm{mM}$ solution of 4 to afford $20.0 \mathrm{mM}$ guest solutions. Titration of the guest solutions into a specified volume of host solution results in an increase of the absorption intensity of the charge-transfer band of the complexes. Treatment of the collected absorption data at $\lambda=403 \mathrm{~nm}$ with a non-linear curve-fitting program afforded the corresponding association constants.

The non-linear curve-fitting was based on the equation:

$A=\left(A_{\infty} /[\mathrm{H}]_{0}\right)\left(0.5[\mathrm{G}]_{0}+0.5\left([\mathrm{H}]_{0}+1 / K_{\mathrm{a}}\right)-\left(0.5\left([\mathrm{G}]_{0}^{2}+\left(2[\mathrm{G}]_{0}\left(1 / K_{\mathrm{a}}-[\mathrm{H}]_{0}\right)\right)+\left(1 / K_{\mathrm{a}}+[\mathrm{H}]_{0}\right)^{2}\right)^{0.5}\right)\right)$

Where $A$ is the absorption intensity of the charge-transfer band $(\lambda=403 \mathrm{~nm})$ at $[\mathrm{G}]_{0}$, $A_{\infty}$ is the absorption intensity of the charge-transfer band $(\lambda=403 \mathrm{~nm})$ when the host is completely complexed, $[\mathrm{H}]_{0}$ is the fixed initial concentration of the host, and $[\mathrm{G}]_{0}$ is the initial concentration of the guest.

References: Connors, K. A. Binding Constants; Wiley: New York, 1987. Corbin, P. S. Ph.D. Dissertation, University of Illinois at Urbana-Champaign, Urbana, IL, 1999. Ashton, P. R.; Ballardini, R.; Balzani, V.; Belohradsky, M.; Gandolfi, M. T.; Philp, D.; Prodi, L.; Raymo, F. M.; Reddington, M. V.; Spencer, N.; Stoddart, J. F.; Venturi, M.; Williams, D. J. J. Am. Chem. Soc. 1996, 118, 4931-4951. 

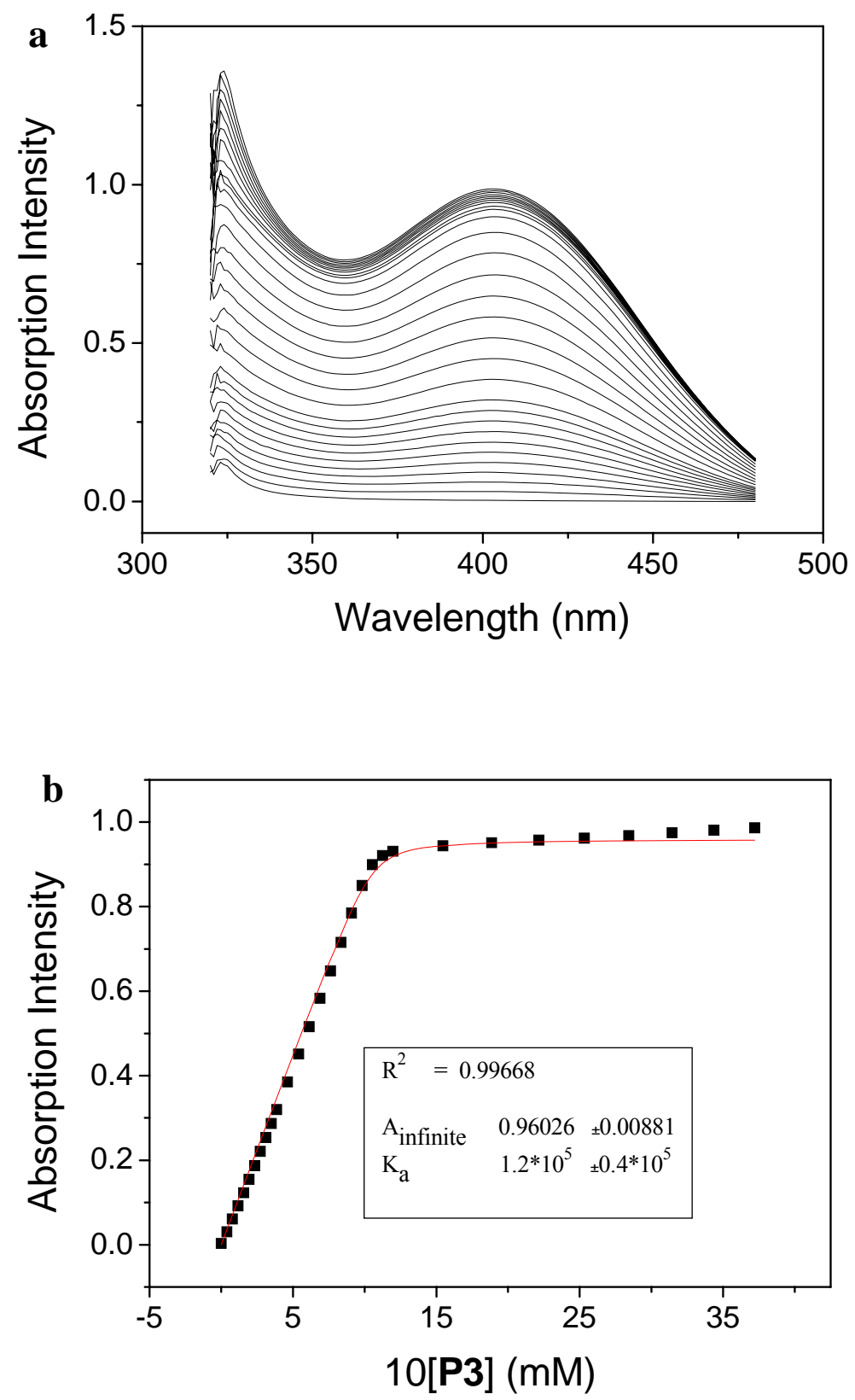

FIGURE S1. (a) The absorption spectral changes of cryptand $4(1.00 \mathrm{mM})$ upon addition of P3 and (b) the absorption intensity changes at $\lambda=403 \mathrm{~nm}$ upon addition of $\mathbf{P} 3$ (from 0 to 3.72 $\mathrm{mM}$ ). The red solid line was obtained from the non-linear curve-fitting using Eq. S1. 

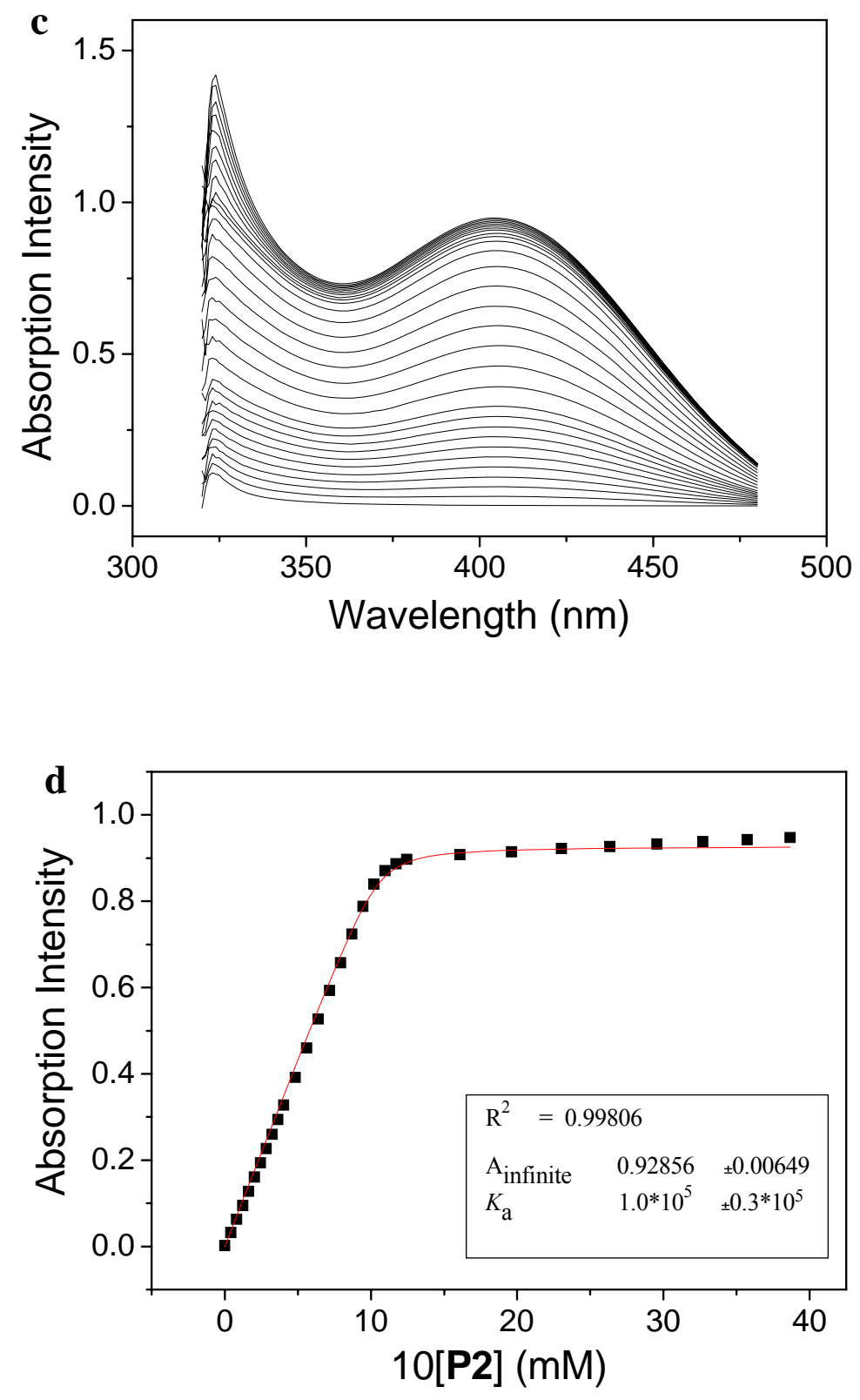

FIGURE S2. (c) The absorption spectral changes of cryptand $4(1.00 \mathrm{mM})$ upon addition of P2 and (d) the absorption intensity changes at $\lambda=403 \mathrm{~nm}$ upon addition of $\mathbf{P 2}$ (from 0 to 3.87 $\mathrm{mM}$ ). The red solid line was obtained from the non-linear curve-fitting using Eq. S1. 

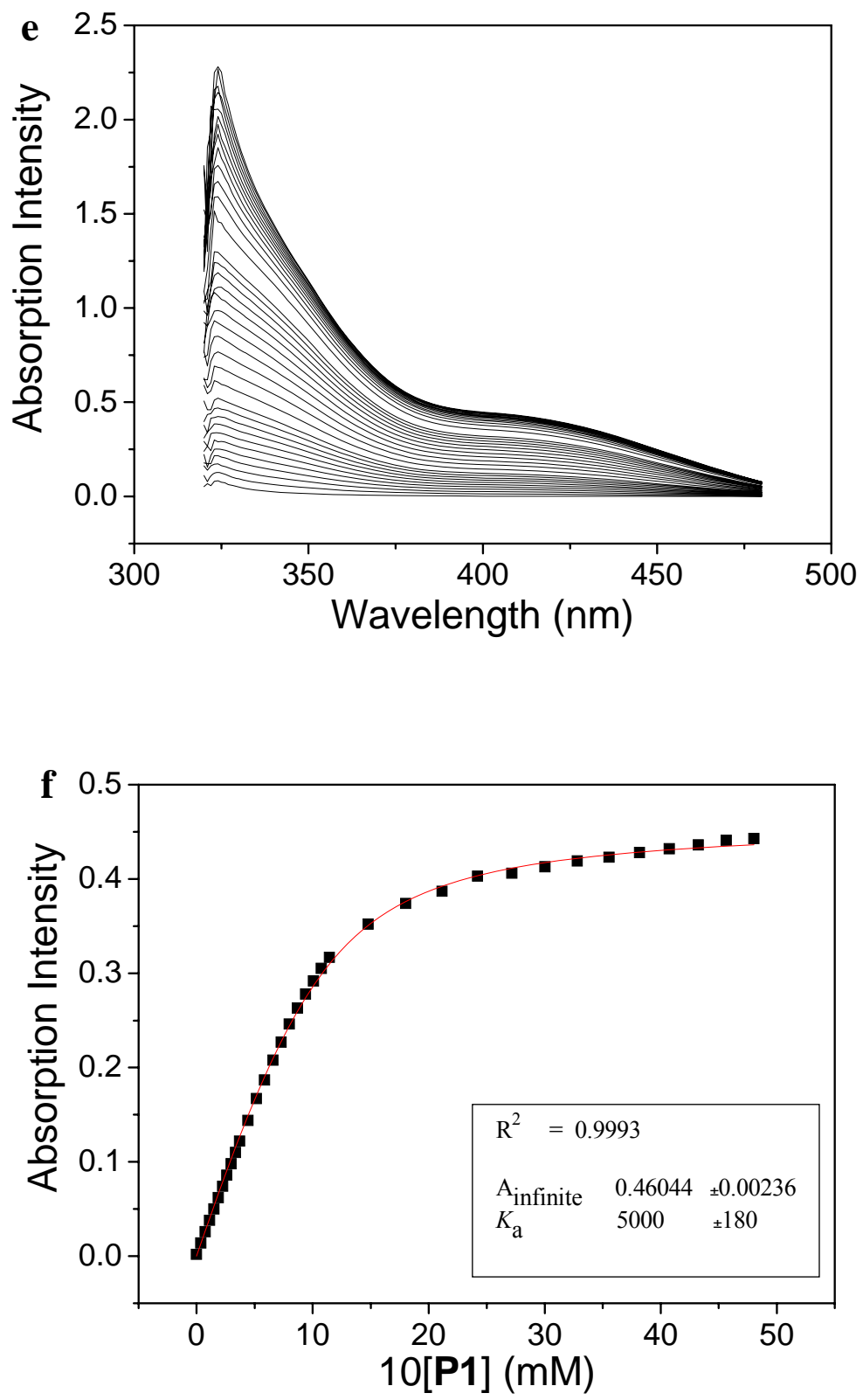

FIGURE S3. (e) The absorption spectral changes of cryptand 4 (1.00 mM) upon addition of P1 and (f) the absorption intensity changes at $\lambda=403 \mathrm{~nm}$ upon addition of $\mathbf{P 1}$ (from 0 to 4.80 $\mathrm{mM}$ ). The red solid line was obtained from the non-linear curve-fitting using Eq. S1. 


\section{2. ${ }^{1} \mathrm{H}$ NMR spectra of $4 \cdot \mathrm{P} 2$ and $4 \bullet \mathrm{P} 3$ with integration values}
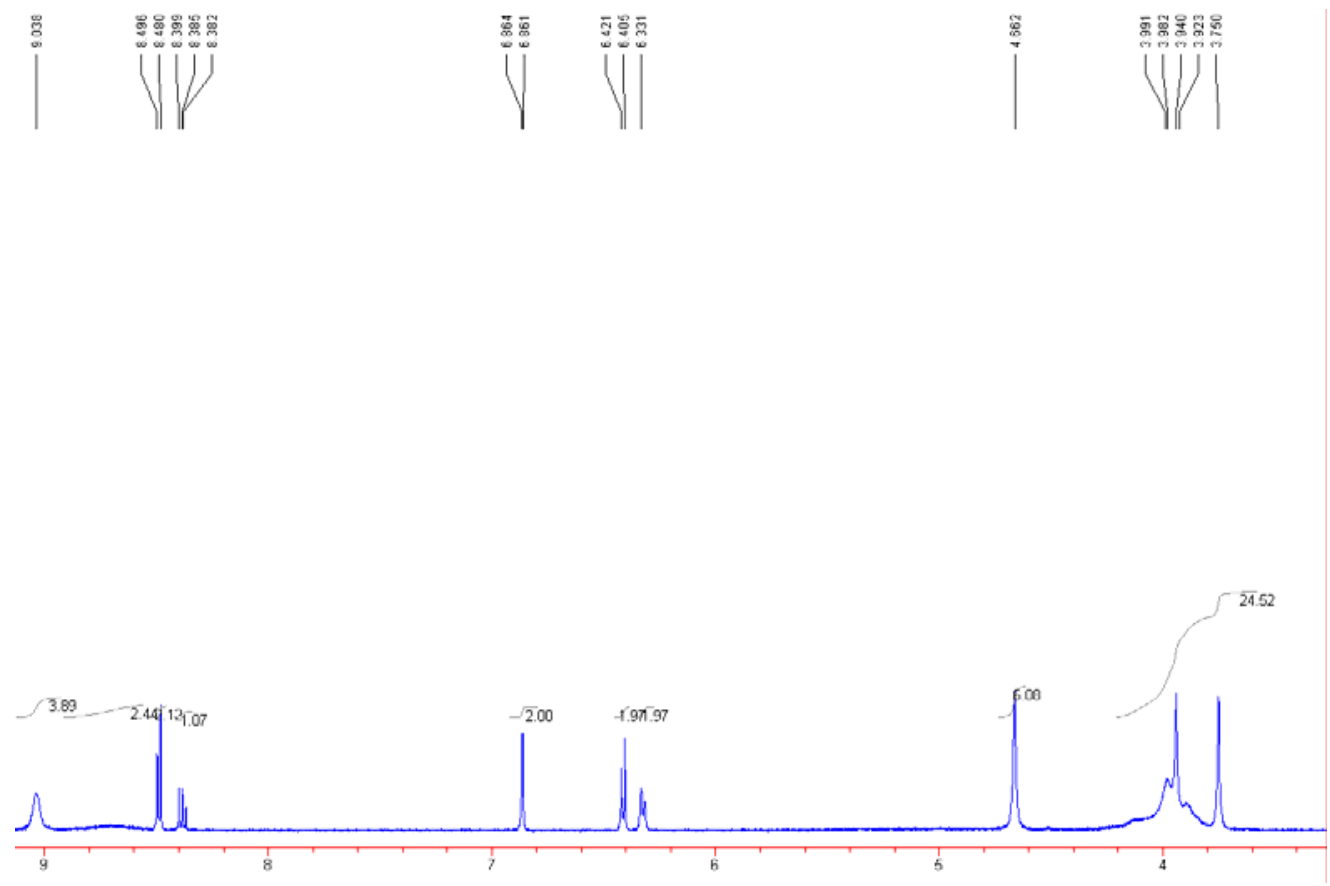

FIGURE S4. Partial proton NMR spectrum ( $500 \mathrm{MHz}$, acetone- $\left.d_{6}, 22{ }^{\circ} \mathrm{C}\right)$ of $2.00 \mathrm{mM} 4$ and

P3.
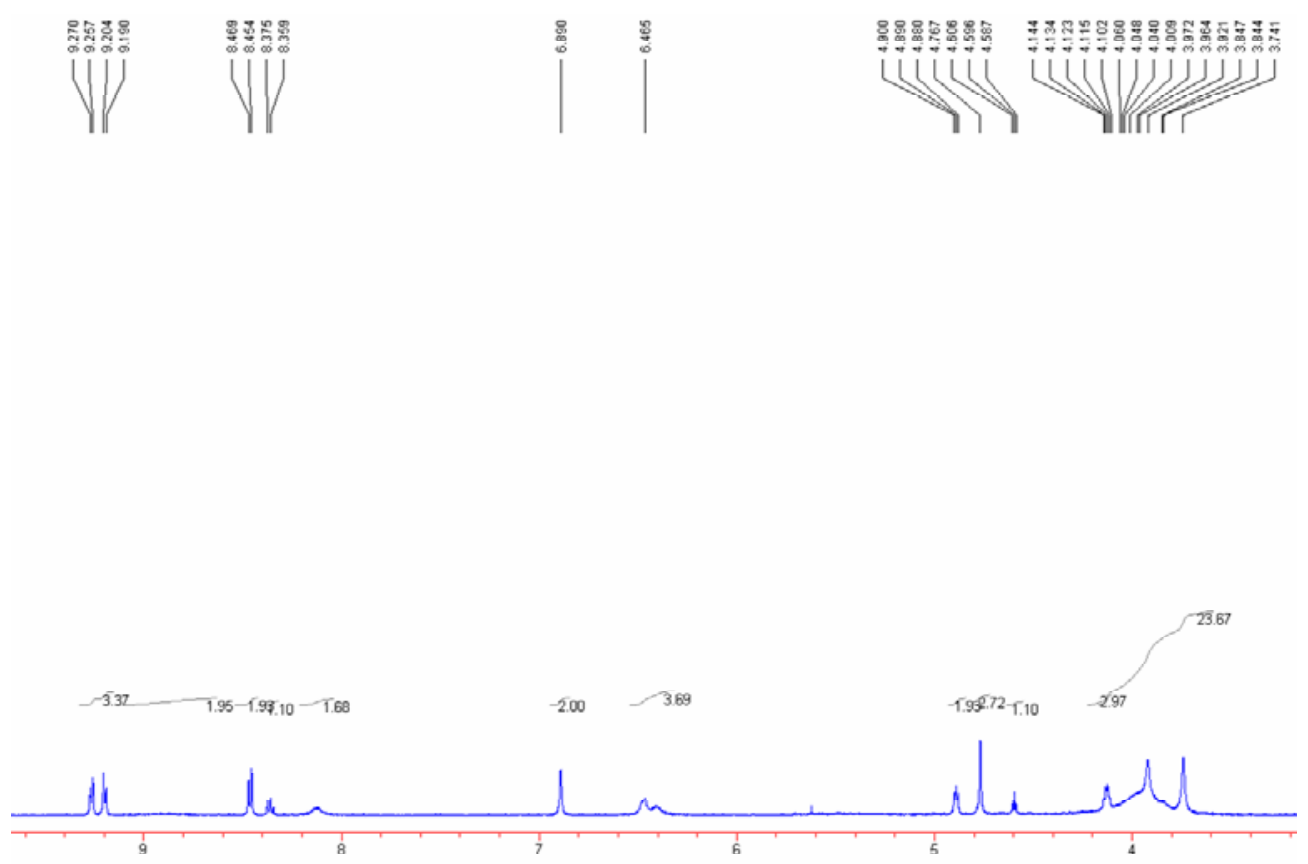

FIGURE S5. Partial proton NMR spectrum (500 MHz, acetone- $\left.d_{6}, 22{ }^{\circ} \mathrm{C}\right)$ of $2.00 \mathrm{mM} 4$ and

P2. 
3. HMQC spectrum of a solution of 4 and $P 2$.

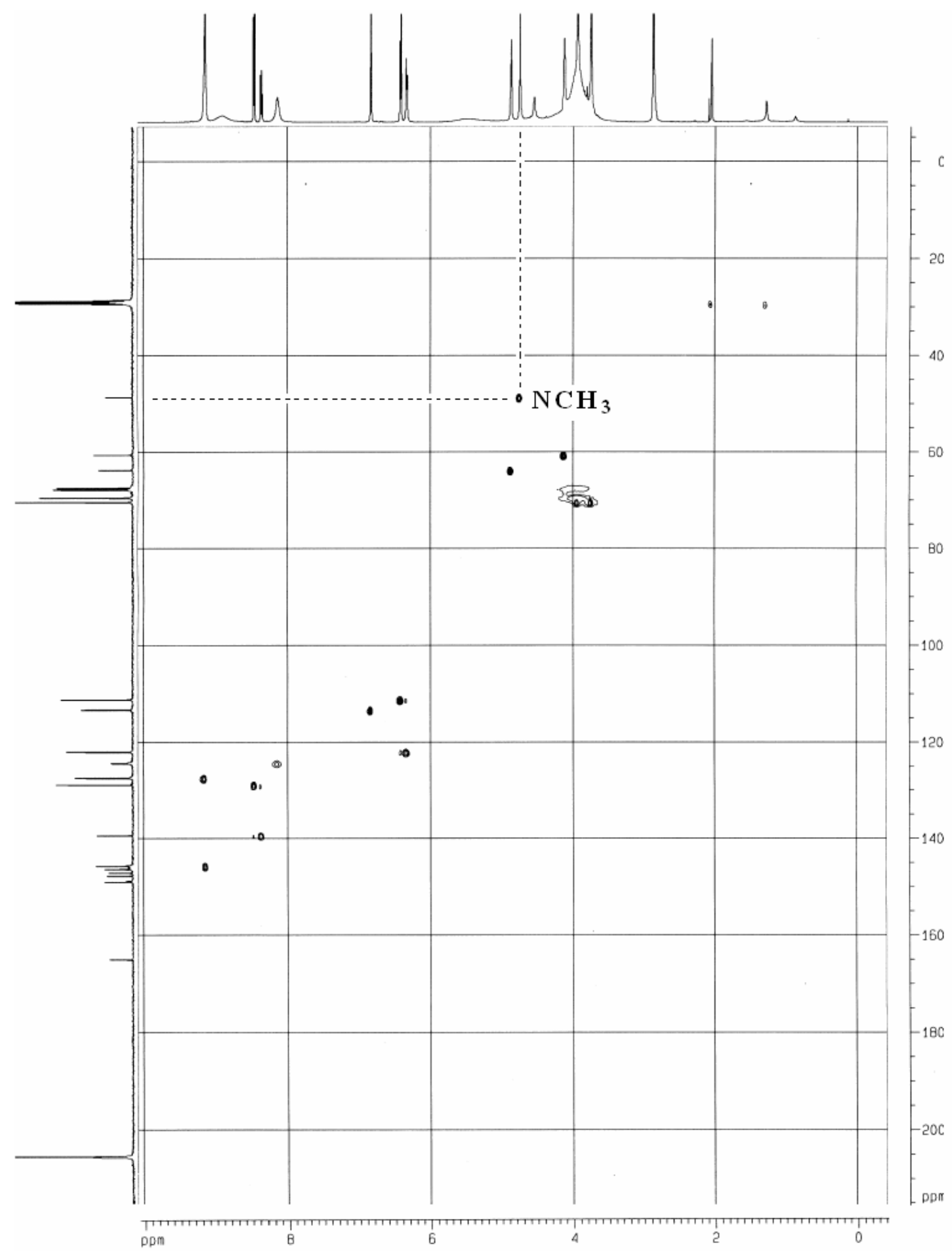




\section{X-ray analysis data of $4 \cdot P 2$.}

Crystallographic data: block, yellow, $0.26 \times 0.21 \times 0.08 \mathrm{~mm}^{3}, \mathrm{C}_{52} \mathrm{H}_{65} \mathrm{~F}_{12} \mathrm{~N}_{3} \mathrm{O}_{14} \mathrm{P}_{2}, F W$ 1246.01, triclinic, space group $P \overline{1}, a=11.6015(18), b=13.783(2), c=19.737(3) \AA, \alpha=98.258(2)^{\circ}, \beta=$ $104.045(2)^{\circ}, \gamma=105.721(2)^{\circ}, V=2872.2(8) \AA^{3}, Z=2, D_{\mathrm{c}}=1.441 \mathrm{~g} \mathrm{~cm}^{-3}, T=100(2) \mathrm{K}, \mu=0.180$ $\mathrm{mm}^{-1}, 25190$ measured reflections, 12537 independent reflections, 725 parameters, 0 restraints, $F(000)=1296, R_{1}=0.0946, w R_{2}=0.2260$ (all data), $R_{1}=0.0756, w R_{2}=0.2125[I>2 \sigma(I)]$, max. residual density $1.639 \mathrm{e} \bullet \AA^{-3}$, and goodness-of-fit $\left(F^{2}\right)=1.144$.

\section{X-ray analysis data of $4 \cdot P 3$.}

Crystallographic data: yellow, $0.35 \times 0.30 \times 0.20 \mathrm{~mm}^{3}, \mathrm{C}_{51} \mathrm{H}_{57} \mathrm{~F}_{12} \mathrm{~N}_{3} \mathrm{O}_{13} \mathrm{P}_{2}, F W$ 1209.94, triclinic, space group $P \overline{1}, a=12.4297(12), b=14.3880(14), c=15.8418(15) \AA, \alpha=95.354(2)^{\circ}, \beta=$ 90.600(2) $)^{\circ}, \gamma=108.356(2)^{\circ}, V=2674.9(4) \AA^{3}, Z=2, D_{\mathrm{c}}=1.502 \mathrm{~g} \mathrm{~cm}^{-3}, T=100(2) \mathrm{K}, \mu=0.190$ $\mathrm{mm}^{-1}, 22853$ measured reflections, 11685 independent reflections, 734 parameters, 0 restraints, $F(000)=1252, R_{1}=0.0610, w R_{2}=0.1282$ (all data), $R_{1}=0.0461, w R_{2}=0.1186[I>2 \sigma(I)]$, max. residual density $0.598 \mathrm{e} \bullet \AA^{-3}$, and goodness-of-fit $\left(F^{2}\right)=1.026$. 
6. A thermal ellipsoid plot of the X-ray crystal structure of $4 \cdot P 1$ with $50 \%$ probability

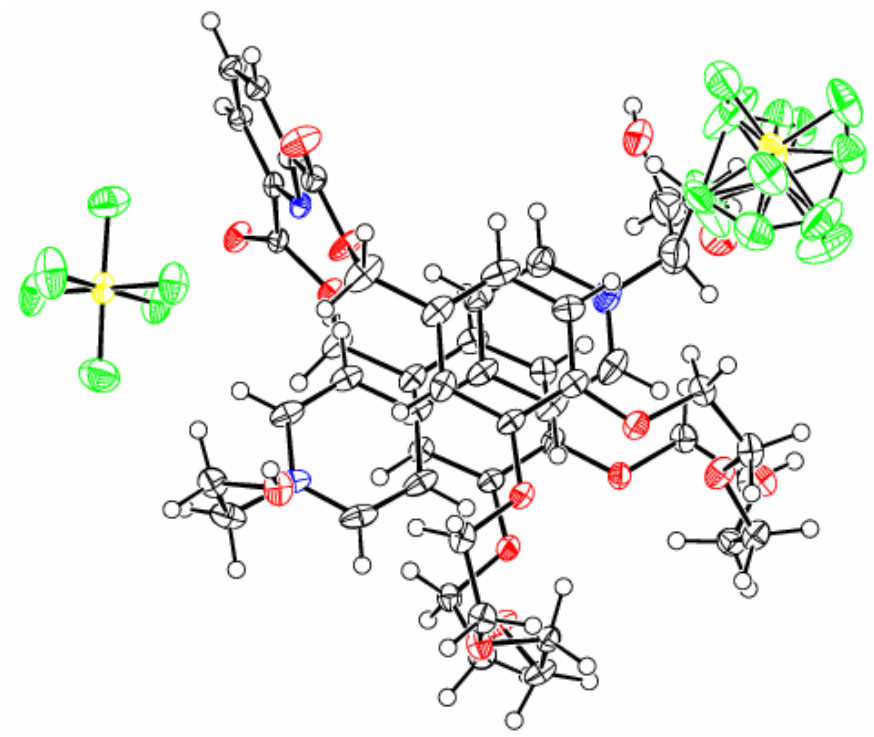

7. A thermal ellipsoid plot of the X-ray crystal structure of $4 \cdot P 2$ with $50 \%$ probability

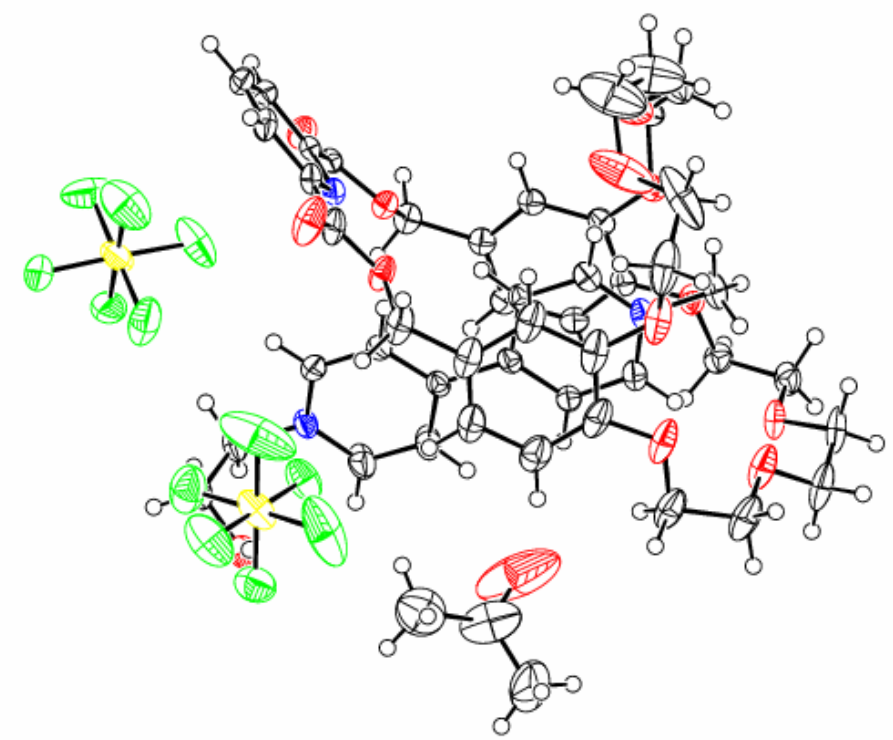


8. A thermal ellipsoid plot of the X-ray crystal structure of $4 \cdot P 3$ with $50 \%$ probability
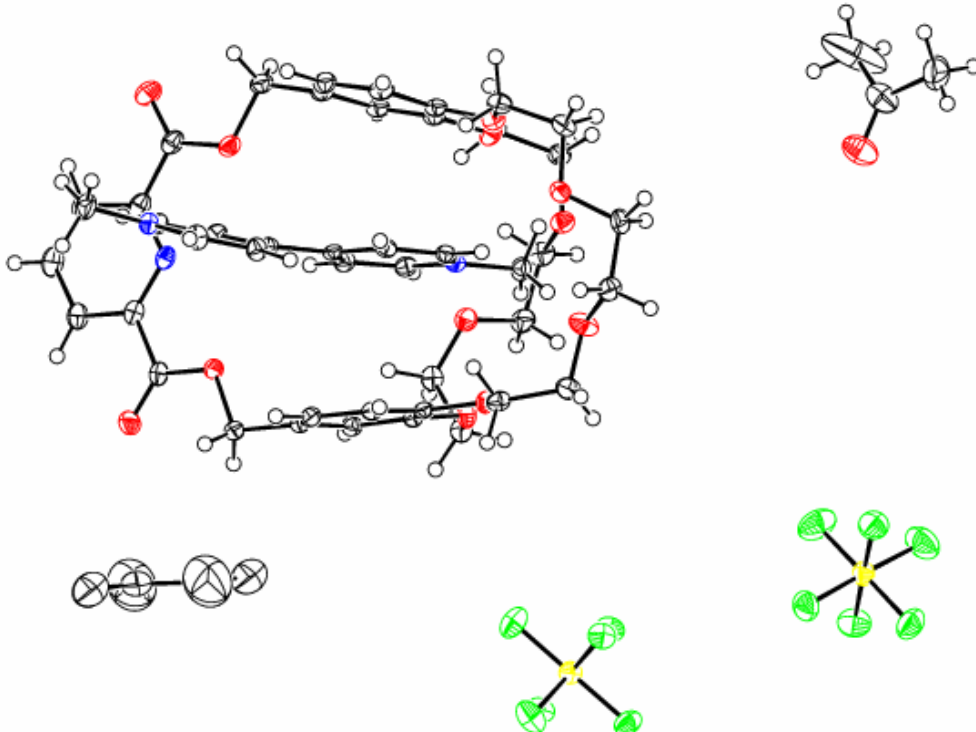
9. Calculations of distribution maps of the Mulliken charges of P1 and P3 at the AM1 level.

Gaussian $03 \mathrm{~W}$ version 6.0 was used in the calculations of distribution maps of the Mulliken charges of P1, P2, and P3. The structures of these three guests were created with ChemDraw Ultra 8.0, geometry-optimized with Chem3D Ultra 8.0 at the AM1 level, and inputted into the Gaussian Program. Then distribution maps of the Mulliken charges were calculated at the AM1 level with the Gaussian program.
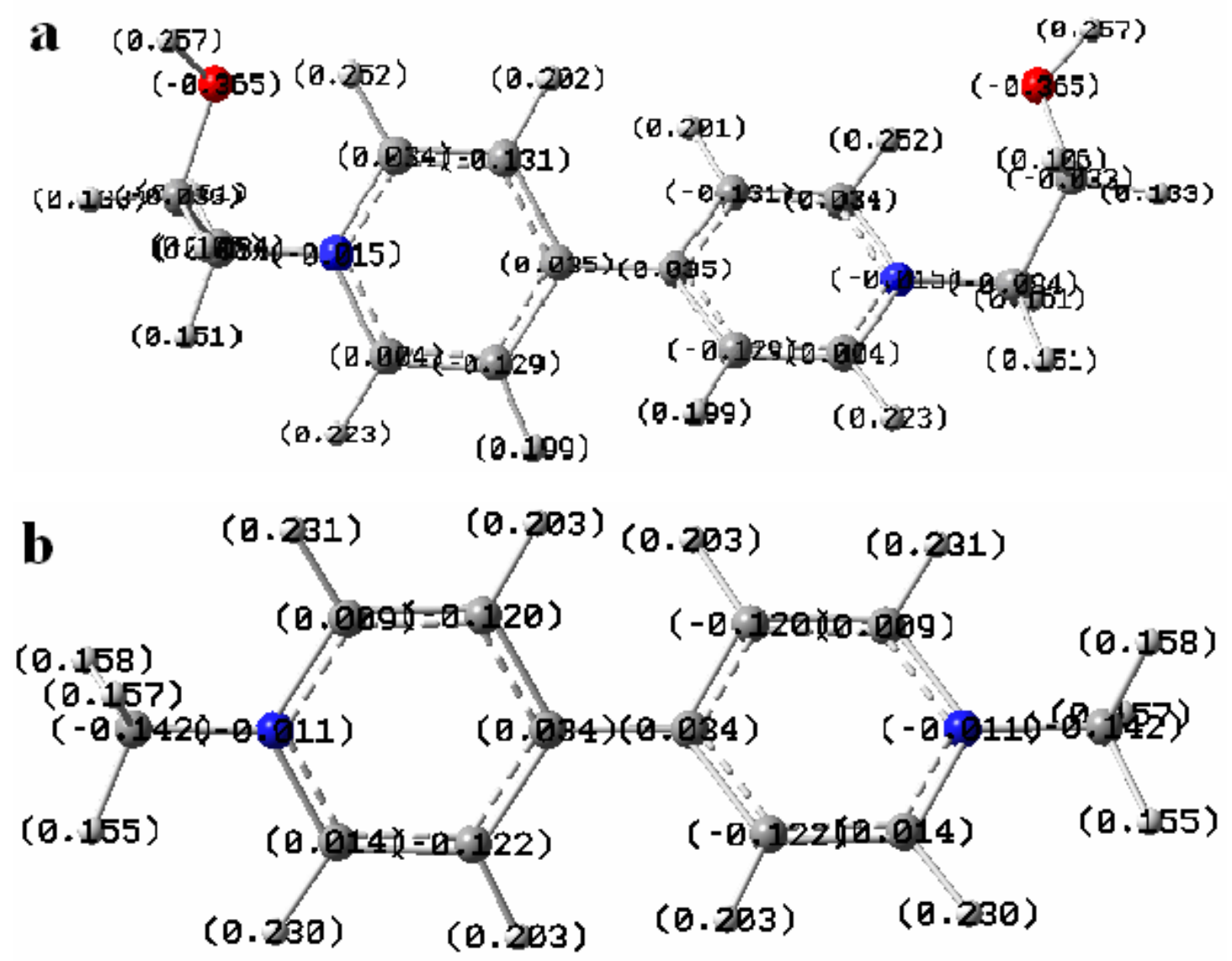

FIGURE S6. Distribution map of the Mulliken charges of P1 (a) and P3 (b) at the AM1 level as determined with the Gaussian program. Carbons are gray, nitrogens are blue, hydrogens are white, and oxygens are red. 